\title{
ВНЕДРЕНИЕ МОДЕЛИ РАЗВИТИЯ ИНКЛЮЗИВНОГО ОБРАЗОВАНИЯ С УЧЕТОМ ЭТНОКУЛЬТУРНЫХ ОСОБЕННОСТЕЙ СТРАН (РОССИЯ И КЫРГЫЗСТАН)
}

\section{IMPLEMENTING THE MODEL OF \\ INCLUSIVE L EDUCATION TAKING \\ INTO ACCOUNT ETHNO-CULTURAL \\ PECULIARITIES OF COUNTRIES \\ (RUSSIA AND KYRGYZSTAN)}

M. Suchkov

Summary: The author describes the specifics of implementing the model of inclusive professional education, taking into account the ethno-cultural characteristics of countries (Russia and Kyrgyzstan). The educational technologies and methods used in professional educational institutions in Kyrgyzstan are presented, based on the life values of the Kyrgyz people, which are reflected in famous proverbs and sayings. The author presents an elective course developed in the framework of the model for students of Kyrgyzstan and Russia "Ethno-cultural aspects of introducing the ideas of inclusive education". Author offers to use several Kyrgyz and Russian literary works in students' performances activities aimed to form humanistic and moral values.

Keywords: inclusive education, students with disabilities, model of education development, ethno-cultural peculiarities, life values, cognitive characteristics

\section{Введение}

$\mathrm{y}$ спех внедрения педагогических моделей в разных странах, на наш взгляд, во многом зависит от присущих той или иной стране культурных, языковых особенностей, принятых в обществе социальных норм. В данном дискурсе речь идет о согласованной и логичной взаимозависимости между внедряемой моделью и социокультурной средой. Мы можем провести сравнение с гармоничным состоянием в природном мире. Например, семена не прорастут без соответствующего климата, температуры, структуры почвы. Деревья могут цвести, но не дадут плодов из-за отсутствия тепла, солнечного света и соответствующей среды для произрастания.

В сфере образования, как и в природном мире, также необходимы гармония, созвучие и сообразность. Обращаясь к инклюзивному образованию, мы подчеркиваем необходимость гармоничного взаимодействия между внедрением инклюзивного подхода в образовании и

\author{
Сучков Максим Александрович \\ К.э.н., дочент, Кыргызский филиал ФГБОУ ВО “Казанский \\ национальный исследовательский технологический \\ университет", г. Кант, Кыргызская Республика \\ maksim-suchkov@inbox.ru
}

Аннотация: В статье автор описывает особенности внедрения модели инклюзивного профессионального образования с учетом этнокультурных особенностей стран (России и Кыргызстана). Представлены используемые технологии, методы и средства обучения в профессиональных учебных заведениях Кыргызстана с опорой на жизненные ценности кыргызского народа, которые находят отражение в известных пословицах, поговорках, высказываниях. Автор представляет разработанный в рамках модели элективный курс для студентов Кыргызстана и России по теме «Этнокультурные аспекты внедрения идей инклюзивного образования». Автором предложено использование некоторых кыргызских и русских литературных произведений в творческой деятельности студентов, направленных на приобщение их к гуманным и духовно-нравственным ценностям.

Ключевые слова: инклюзивное образование, студенты с ограниченными возможностями здоровья (ОВЗ), модель развития образования, этнокультурные особенности, жизненные ценности, когнитивный признак.

особенностями мировоззрения, жизненных ценностей и традиций того или иного этноса, даже если эти особенности в определенной степени тормозят внедрение идеи инклюзии. Учет их в образовательной практике крайне необходим, что впоследствии способствует успешной реализации технологий, методов обучения, воспитания. Разработанная нами модель развития инклюзивного образования с учетом этнокультурных особенностей внедрена в профессиональных учебных заведениях Кыргызстана (Кыргызский филиал Федерального государственного бюджетного образовательного учреждения «Казанский национальный исследовательский технологический университет», г. Кант) и в России (Казанский инновационный университет им. В.Г. Тимирясова, Казань).

Исследования отечественных и зарубежных практик внедрения образовательных моделей в сфере инклюзивного образования с учетом этнокультурных факторов

Для разработки и последующего внедрения модели 
развития инклюзивного образования с учетом этнокультурных особенностей в Республике Кыргызстан и России мы проанализировали работы по изучению кыргызского менталитета 3. Дербишевой [1], русской культуры И.В. Кондакова [2], философского анализа русского менталитета А.А. Григорьевой [3]. Большую ценность при проектировании нашей модели представили труды О.А. Корнилова [4], посвященные изучению языковой картины мира. Он проанализировал особенности воздействия среды на образ мышления нации. Это воздействие рассматривается ученым на уровне психологии, физиологии и социологии.

Большой интерес представляют уже внедренные модели развития инклюзивного образования в России. Модель организации инклюзивного образовательного процесса на примере общеобразовательной санаторной школы г. Нижневартовск представлена Н.М. Беткер, М.И. Еременко, Н.В. Лопаткиной [5]. Авторы изучили особенности разработки адаптированной образовательной программы для детей с ограниченными возможностями здоровья (ОВ3). Подходы и структура модели обучения межкультурной коммуникации в высшем учебном заведении проанализированы В.Д. Грищенко [6]. В модели автора представлены различные упражнения, способствующие эффективной межкультурной коммуникации (межкультурные проекты, ролевые и деловые игры, интервью и др.). Модель развития межкультурной компетенции иностранных учащихся изучена С.И. Шевелевой [7]. Автор отмечает необходимость использования игровых технологий, дискуссии в повышении готовности к межкультурному обучению иностранных студентов на этапе предвузовской подготовки.

Особенности межкультурного взаимодействия в системе высшего образования исследованы нами в трудах таких зарубежных ученых, как: О. Кехагиа [8], Р. Линднер [9]. Авторы описывают необходимость внедрения курса «Language for Special Purposes» в поликультурной среде («Язык для специальный целей»), благодаря которому студенты приобретают необходимые навыки для эффективной межкультурной коммуникации.

В разработанной нами модели важно учитывать методики и технологии инклюзивного образования. В модели инклюзивного образования, разработанной и описанной С. Лэнд [10], предлагается усиливать сотрудничество в преподавании, привлекая специальных педагогов-психологов к совместной работе, а также используя методы параллельного обучения и интерактивные средства, формальные и неформальные методы оценки успеваемости студентов.

Внедрение модели развития инклюзивного образования с учетом этнокультурных особенностей в Республике Кыргызстан

Важнейшими компонентами нашей модели являются содержательный и технологический, включающие в себя технологии, методы и средства обучения, особенности организации учебно-воспитательного процесса и внеучебной деятельности. При внедрении данных компонентов в образовательной практике профессиональных учебных заведений Кыргызстана мы учитывали своеобразие кыргызского «видения мира», психологического портрета этноса с присущими ему мировоззрением и мироощущением. Эти особенности, безусловно, нашли отражение в кыргызском языке, известных пословицах и поговорках. В них раскрываются определенные жизненные ценности и установки. Мы представили некоторые особенности миропонимания кыргызского народа, а также когнитивные признаки, представляющие собой определенные признаки объекта, осознанные человеком и формирующие целую концептосферу (совокупность знаний, концептов об определенном явлении).

Многие жизненные ценности кыргызов отражают принципы инклюзии. Рассмотрим некоторые из них:

1. Надежда на лучшее будущее («Жамандыкты амандык жеңет» - «Все плохое можно победить»).

2. Сплоченность народа («Жалгыз жүрүп жол тапканча, көп менен бирге адаш» - «Лучше заблудиться всем, нежели найти дорогу в одиночку»).

3. Миролюбие и благородство («Эптүү сүйлэп чөгөлөсө, кулдук кылып, баш ургун» - «Прости того, кто говорит искренне, склонив перед тобой голову») [1].

Ниже мы представили наиболее яркие жизненные ценности и когнитивные признаки кыргызского народа, с учетом которых мы реализуем инклюзивный подход в обучении и воспитании в профессиональных учебных заведениях, применяем определенные технологии организации учебной и внеучебной деятельности (таб.1)

Другим важным компонентом нашей модели является элективный курс для студентов профессиональных учебных заведений «Этнокультурные аспекты внедрения идей инклюзивного образования» (36 часов). Данный курс может быть проведен как для студентов вузов Кыргызстана, так и России, однако некоторые блоки курса могут отличаться (таб.2).

Тема 1. Инклюзивное образование и инклюзивное общество: мое видение (2 часа практического занятия и 4 часа лекции). Во время вводного занятия студенты в форме дискуссии выражают свое мнение о том, что представляют собой в их понимании такие термины, как: инклюзивное образование, инклюзия, особые образовательные потребности, ограниченные возможности здоровья, инклюзивная культура. Далее на лекционном занятии студенты знакомятся с теоретико-методологическими и философскими основами инклюзивного образования. 
Особенности внедрения инклюзивных подходов в обучении в профессиональных учебных заведениях Кыргызстана в призме жизненных ценностей кыргызского народа

Жизненные ценности и когнитивные признаки
кыргызского народа [1]

Философия сплоченности и единства народа - «Тириликтин күчү бирликте») («Сила жизненная в объединении»).

Благополучие не в богатстве - «Мал сактабa, ар сакта» («Храни честь, не храни богатство - СКОТ»).

Решение конфликтов мирным путем - «Таш менен урганды аш менен ур» («Тот, кто ударил камнем, нанеси ответный удар угощением»).

Душевная щедрость и установка на добро «Элге кылган жакшылык жерде калбайт» («Добро для людей не исчезнет в земле»).

Любовь и уважение к отечеству - «Мекенсиз адам - үнсуз булбул») («Человек без дома как молчаливый соловей»).

Терпение - высшее достоинство. - «Сабырдын тубу сары алтын» («Чистое золото находится на дне терпения»).

Труд - ключ к богатству - «Оору эмгектен качат, эмгек көңүлду ачат» («Болезнь сбегает от труда, труд поднимает настроение»).

\section{Внедряемые технологии, методы и средства обучения,} формы учебной и внеучебной деятелности

Разработка студентами инклюзивных групп совместных проектов на тему «Моя профессия мое счастливое будущее».

Проведение психологических тренингов в сту денческих инклюзивных группах, организация совместных творческих занятий. Проведение ролевых игр на тему «Вместе поможем людям, оказавшимся в трудной жизненной ситуации» (участвуют студенты разных специальностей).

Проведение творческих и интеллектуальных конкурсов среди студентов разного уровня благополучия. Наивысшей ценностью конкурса является интеллектуальный или творческий продукт.

Обучение студентов таким технологиям, как: медиация, посредничество, переговоры. Отработка данных методов на практических занятиях.

Проведение научно-практических конференций, круглых столов, семинаров для студентов по теме «Моя роль В становлении гуманного общества».

Формирование знаний о родной культуре через участие студентов в постановке произведений народного творчества. Применение проблемнопоисковых методов обучения, исследовательской деятельности с целью повышения заинтересованности к истории родной страны.

Включение студентов в исследовательские проекты, самостоятельные творческие работы, конкурсы.

Использование методов трудотерапии в инклюзивных студенческих группах: создание керамических, глиняных изделий народного творчества, пошив национальных костюмов, подготовка декораций для студенческой сцены. Организация интеллектуальной трудовой деятельности.

\section{Ожидаемый эффект с точки зрения идеи
инклюзии}

Формируется позитивная установка на счастливое будущее и на профессиональную самореализацию для «ВСЕХ» студентов.

Формируется благоприятный психологический климат в инклюзивной группе, студенты и педагоги объединяются, устраняются барьеры в общении.

Сплочение студентов разного уровня жизни и социального статуса. Студент оценивает себя не по уровню материального достатка, а по трудовой, умственной и творческой деятельности.

Студенты обучаются урегулировать межэтнические, языковые конфликты и другие разногласия в разных жизненных ситуациях.

Формируется гуманное отношение к людям разной этнической, социальной принадлежности и разного состояния здоровья.

Осознание причастности к судьбе родной страны и своего народа, любовь к родине.

Развитие выдержки, терпения, дисциплинированности у студентов инклюзивных групп.

Трудовая деятельность студентов с ОВЗ способствует процессу их социализации. В определенных видах деятельности улучшаются двигательные навыки, речевая деятельность. Трудотерапия В творчестве способствует объединению учащихся разных этнических принадлежностей.

Таблица 2.

Содержание элективного курса «Этнокультурные аспекты внедрения идей инклюзивного образования»

\begin{tabular}{|c|c|c|}
\hline № & Название темы & Количество часов \\
\hline 1 & Инклюзивное образование и инклюзивное общество: мое видение & 4 часа лекции и 2 часа практического занятия \\
\hline 2 & Нормативно-правовое регулирование сферы инклюзивного образования & 4 часа семинарского занятия \\
\hline 3 & Зарубежный опыт реализации инклюзивного образования & 2 часа лекции и 2 часа семинарского занятия \\
\hline 4 & Этнокультурные особенности страны: основные понятия & 2 часа лекции, 2 часа самостоятельной работы, 2 часа учебной дискуссии \\
\hline 5 & Инклюзивное образование и его этнокультурные аспекты & 2 часа лекции и 2 часа практического занятия \\
\hline 6 & Восприятие лиц с ОВЗ разными этносами & 2 часа лекции и 2 часа круглого стола \\
\hline 7 & $\begin{array}{l}\text { Технологии адаптации студентов с ОВЗ, студентов иной языковой и нацио- } \\
\text { нальной принадлежности к обучению в вузе }\end{array}$ & 2 часа лекции и 2 часа творческого занятия \\
\hline 8 & $\begin{array}{l}\text { Инклюзивное образование с учетом этнокультурных особенностей страны: } \\
\text { инновационные идеи }\end{array}$ & 2 часа студенческой конференции и 2 часа выступления с эссе \\
\hline
\end{tabular}


Тема 2. Нормативно-правовое регулирование сферы инклюзивного образования. (4 часа семинарского занятия с использованием поискового метода обучения и обсуждения в группе). Студентам по группам раздаются распечатанные международные документы, национальные нормативно-правовые акты, Концепции, программы, регулирующие разные сферы реализации инклюзивного образования. Каждой группе необходимо найти конкретную статью или пункт, отражающие ту или иную область реализации инклюзивного образования. На следующем этапе студентам необходимо подготовить выступление от своей группы, рассказав коротко о своем нормативно-правовом акте и его роли.

Тема 3. Зарубежный опыт реализации инклюзивного образования (2 часа лекционного занятия с просмотром видеоролика и последующим обсуждением его на семинарском занятии (2 часа)). Студентам представляется для просмотра видеоролик об особенностях реализации инклюзивного образования в США, Канаде, Европе, странах Юго-Восточной Азии, арабских странах, Африке и др.. Студенты знакомятся не только с опытом отдельных зарубежных образовательных организаций, но и изучают особенности оказания социальной поддержки людям с ОВ3, помощи в их социализации и интеграции.

Тема 4 Этнокультурные особенности страны: основные понятия и их характеристики (2 часа лекции, 2 часа самостоятельной работы с научной литературой, 2 часа учебной дискуссии). На лекционном занятии студенты знакомятся с такими понятиями, как: этнос, этническая культура, менталитет, ментальность, традиции, национальный характер, этнические стереотипы, религиозные особенности и др. Изучив данные понятия, студенты получают индивидуальные задания по подготовке их расширенной и углубленной характеристики и по изучению этнокультурных особенностей России (для студентов российских профессиональных учебных заведений) и Кыргызстана (для студентов Кыргызстана). Студенты также изучают культурные особенности других этносов. Во время дискуссии они обмениваются полученными знаниями об особенностях менталитета, стереотипах, жизненных ценностях разных этносов, проводят сравнительный анализ.

Тема 5 Инклюзивное образование и этнокультурные аспекты (2 часа лекции и 2 часа практического занятия с применением игровой технологии). На лекционном занятии учащиеся знакомятся с такими понятиями, как: культурное многообразие, поликультурная образовательная среда, этнорелятивизм, этнотолерантность, этноцентризм, диалог культур. Далее студенты изучают особенности речевого этикета разных народностей, их представления о пространстве и времени, когнитивные признаки, национальную концептосферу, особенно- сти невербального общения разных культур. Во время практического занятия применяется игровая технология, суть которой заключается в следующем: студенты погружаются в поликультурный класс, представляя, что они относятся к разным этническим принадлежностям и владеют разными родными языками, имея при этом базовые знания по основному языку обучения в вузе (для российского вуза - по русскому языку, для Кыргызстана -по кыргызскому). Перед студентами ставится задача - выполнение общего проекта по одной из тем осваиваемой специальности, например: «Инновационное развитие региона», «Решение проблемы безработицы в стране», «Улучшение экологической ситуации в городе» и др. Для осуществления проекта студентам «имитированной» поликультурной группы необходимо преодолеть языковые барьеры в общении, установить эффективную кросскультурную коммуникацию, соблюдая предварительно изученные ими нормы речевого этикета, вербального и невербального общения, свойственного другим культурам. Целью такого занятия является установление положительных контактов с людьми разных этнических принадлежностей, устранение барьеров в общении, конфликтности, стремление к уравновешенности в общении.

Тема 6 Восприятие лиц с ОВЗ разными этносами (2 часа лекционного занятия и 2 часа круглого стола на тему «Национальное восприятие инклюзии и способы формирования позитивной установки в обществе на образовательную и социальную инклюзию»). Студенты знакомятся с особенностями влияния религиозных и культурных убеждений на восприятие «инклюзии» и людей с ОВ3 в обществе и отдельно в системе образования. Рассматриваются этнические стереотипы, негативно или позитивно влияющие на развитие инклюзивного образования. Во время круглого стола студенты предлагают свои идеи о том, как можно преодолеть негативные установки в обществе относительно всеобщего и равного образования, повысить осведомленность среди населения о значимости социальной инклюзии, о межкультурной толерантности. Студенты предлагают свои идеи о внедрении механизма «инклюзивного навигатора» среди общественности (СМИ, пособия, просветительские беседы с родителями детей с ОВ3).

Тема 7. Технологии адаптации студентов с ОВ3, иной языковой и национальной принадлежности к обучению в вузе (2 часа лекционного занятия и 2 часа творческого занятия). На лекционном занятии студенты знакомятся с основами адаптации лиц с ОВ3 к образовательной среде в психолого-педагогическом контексте. Рассматриваются психологические, социальные, языковые и культурные барьеры на пути к успешной интеграции. Студенты изучают способы оказания психологической помощи своим сверстникам с нарушениями в развитии, особенности психолого-педагогического сопровожде- 
ния учебного процесса. Данный блок курса особенно важен для студентов психолого-педагогических специальностей. Во время практического занятия студенты участвуют в проектировании учебного процесса с применением различных методик и технологий инклюзивного образования.

Тема 8 Инклюзивное образование с учетом этнокультурных особенностей страны: инновационные идеи (проведение студенческой конференции на тему «Устойчивое развитие образования в призме инклюзии» (2 часа) и участие студентов в конкурсе на лучшее эссе на тему «Моя роль в становлении инклюзивного общества: профессиональный контекст»).

Итак, элективный курс, описанный выше, способствует расширению этнокультурного мировоззрения студентов, формированию гуманного и уважительного отношения к людям разных возможностей и способностей, этнической принадлежности.

С целью приобщения к этнокультурным традициям, изучения культурных установок, ментальных приоритетов своего родного этноса мы предлагаем использование произведений народного творчества в организации творческой деятельности студентов. Студенты могут организовать небольшие театральные постановки по сюжетам наиболее известных фольклорных произведений, имеющих этнопедагогическую направленность. Например, студенты из Республики Кыргызстан могут организовать такие постановки по сюжетам известного кыргызского эпоса «Манас». В нем подчеркивается уважительное отношение к женщинам, старшим поколениям. В произведении главными достоинствами человека являются благородство, терпимость, гуманное отношение к людям, трудолюбие, щедрость, почтительное отношение к родному языку и традициям.

Для студентов российского вуза приобщение к ин- клюзивным ценностям и принципам может быть предложено через использование в творческой деятельности постановки таких известных русских произведений, как: роман «Накануне» И.С. Тургенева (образ героини, имеющей серьезные стремления помогать нуждающимся и слабым людям, несмотря на свое происхождение и статус, не позволяющие в те времена допускать такое благородное отношение к людям более низкого положения в обществе), «Уроки французского» В.Г. Распутина (учитель, проявивший истинное желание помочь ученику, оказавшемуся в трудной жизненной ситуации), «Дети подземелья» В.Г. Короленко (влияние среды и жизненных обстоятельств на становление личности, тема понимания, милосердия, доброты).

В российских и кыргызских вузах могут быть использованы также элементы народного творчества других народов, имеющих гуманную направленность.

\section{Выводы}

В данном исследовании мы «обрисовали» основные контуры внедряемых технологий, методов и средств обучения, организации внеучебной деятельности, направленных на расширение этнокультурного и инклюзивного мировоззрения студентов. На примере Республики Кырыгзстан мы раскрыли особенности мировоззрения кырыгзского народа в лингвокогнитивной призме и то, какие образовательные технологии наиболее гармонично сочетаются с ними. Предметом наших дальнейших исследований станут особенности внедрения разработанной нами модели в отношении самого ответственного за обучение и воспитание субъекта образовательного процесса - педагога, от которого зависит создание благоприятной атмосферы для обучения, инклюзивной культуры образовательного учреждения и эффективность обучения, воспитания и социализации студентов профессиональных учебных заведений.

\section{ЛИТЕРАТУРА}

1. Дербишева 3.К. Кыргызский этнос в зеркале языка: монография. - 2-е изд. -М.:ФЛИНТА, 2015, 211 с.

2. Кондаков И.В. Ментальная доминанта российской цивилизации // Философские науки. 2010. № 3. С. 23-32

3. Григорьева А.А. Русский менталитет: сущность и структура (социально-философский анализ): дис. ... канд. фил. наук: 09.00.11 / Григорьева Анастасия Александровна. - Томск, 2008. - 120 c.

4. Корнилов 0.А. Языковые картины мира как производные национальных менталитетов. - 2-е изд., испр. и доп. — М.: ЧеРо, 2003,349 с.

5. Беткер Л.М., Еременко М.И., Лопаткина Н.В. Организация инклюзивного образования обучающихся с ограниченными возможностями здоровья и/или детей-инвалидов: методические материалы для руководителей, педагогов, специалистов сопровождения (учителей-логопедов, учителей дефектологов, педагогов-психологов, социальных педагогов, тьюторов). - Ханты-Мансийск: РИО ИРО, 2016, 90 с.

6. Грищенко В.Д. Практико-ориентированная модель обучения межкультурной коммуникации в вузе // Вестник Брянского государственного университета. 2013.

7. Шевелева С.И. Модель формирования основ межкультурной компетенции иностранных обучающихся на этапе предвузовской подготовки // Современные проблемы науки и образования. 2015. № 4. С.56-62

8. Nteliou E., Kehagia 0. Intercultural perceptions among undergraduate students in English for Business and Economics courses // International Journal of Language, Translation and Intercultural Communication. 2016. Vol. 4. P. 98-109. URL: https://doi.org/10.12681/ijltic.10345 
9. Lindner R. Introducing a Micro-Skills Approach to Intercultural Learning to an English for Specific Purposes Course for Students of Sociology // Scripta Manent. 2010. № 5 (1-2). P. 9-24.

10. Land S. Effective teaching practices for students in inclusive classrooms.URL: https://education.wm.edu/centers/ttac/resources/articles/inclusion/effectiveteach/

11. Hammer, M.R., Bennett, M.J., \& Wiseman, R. (2003). Measuring intercultural sensitivity: The intercultural development inventory. International Journal of Intercultural Relations, 27(4),421-433

(с Сучков Максим Александрович (maksim-suchkov@inbox.ru).

Журнал «Современная наука: актуальные проблемы теории и практики»

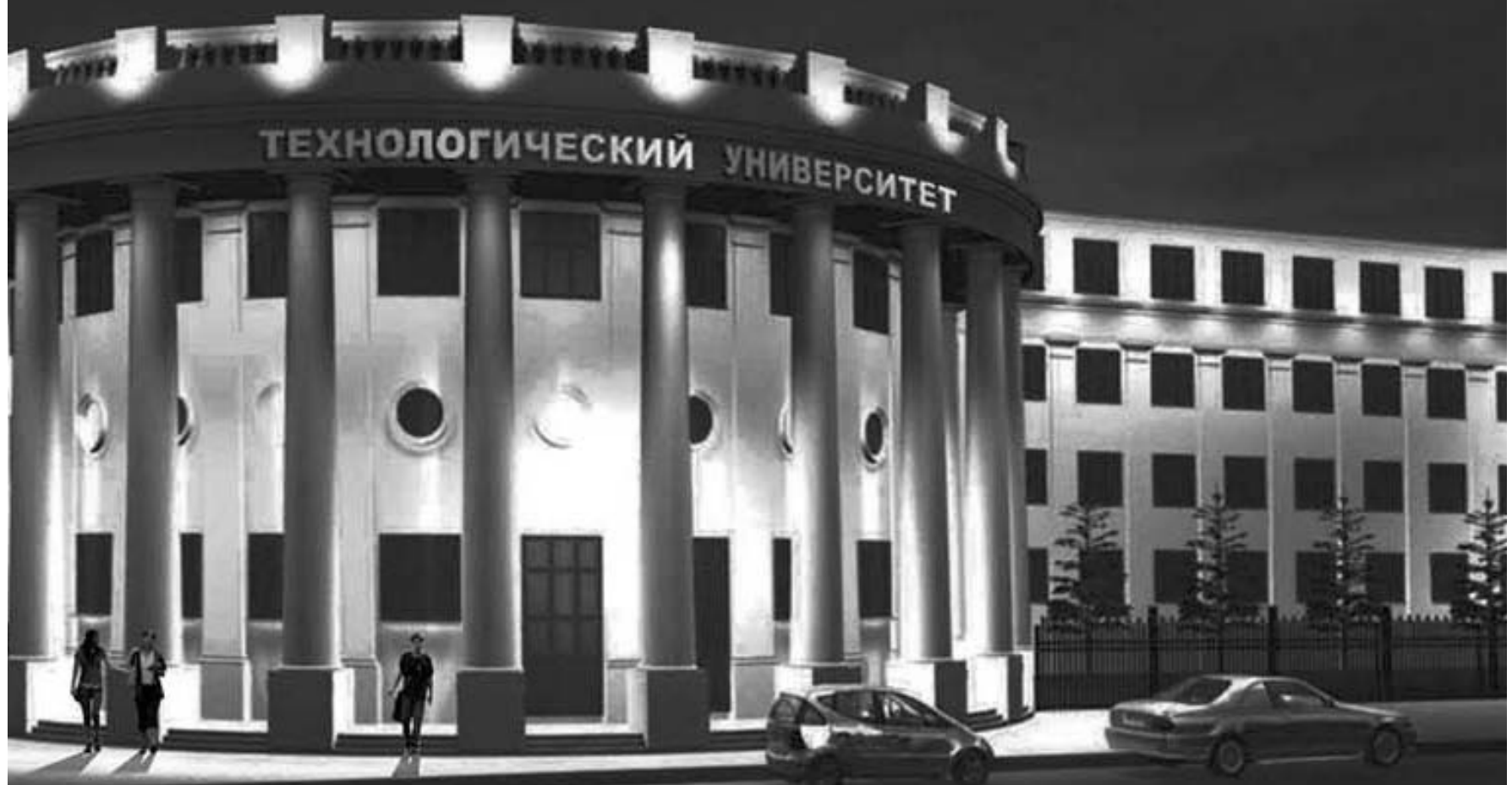

Казанский национальный исследовательский технологический университет 